\title{
Prevention of hospital-acquired hypokalemia in children receiving maintenance fluid therapy
}

\author{
Kazunari Kaneko", Ken Yoshimura, Takahisa Kimata, Kohsuke Ishii, Tetsuya Kitao, Sachiyo Tanaka, \\ Shoji Tsuji
}

Department of Pediatrics, Kansai Medical University, Osaka, Japan

Email: "kanekok@hirakata.kmu.ac.jp

Received 14 January 2012; revised 10 April 2012; accepted 22 April 2012

\begin{abstract}
Objective: It has been suggested that the use of hypotonic intravenous fluid (IVF) puts hospitalized children at a greater risk of developing hyponatremia in children with increased arginine vasopressin (AVP) production. To reduce its risk, the National Patient Safety Agency in UK issued alert 22 in 2007, of which recommendations were to use isotonic solutions for these children at risk of hyponatremia, instead of the previously most commonly used IVF $(0.18 \%$ saline/ 4\% dextrose) for maintenance fluid therapy. Recent observations, however, revealed that hypokalemia are also common in hospitalized patients who do not receive potassium in their IVF. This study was conducted to validate the potassium added IVF for the prevention of hospital-acquired hypokalemia in maintenance fluid therapy. Design: For maintenance fluid therapy, a commercially available IVF solution in Japan named as Solita-T2 ${ }^{\mathrm{R}}$ (Na $84 \mathrm{mmol} / \mathrm{L}, \mathrm{K} 20$ $\mathrm{mmol} / \mathrm{L}, \mathrm{Cl} 66 \mathrm{mmol} / \mathrm{L}$, glucose $3.2 \%$ ) was infused for 41 sick children with a median age of 3.01 years. Its composition is close equivalent to $0.45 \%$ saline $/ 5 \%$ dextrose ( $\mathrm{Na} 77 \mathrm{mmol} / \mathrm{L}, \mathrm{K} 0 \mathrm{mmol} / \mathrm{L}, \mathrm{Cl} 77 \mathrm{mmol} / \mathrm{L}$, dextrose $5 \%$ ) except $K$ content. The patients in states of AVP excess were excluded from the analysis. Results: Median serum potassium value did not drop significantly at a median interval of 48 hours (before IVF: $4.30 \mathrm{mmol} / \mathrm{L}$, after IVF: $4.10 \mathrm{mmol} / \mathrm{L}, \mathrm{p}>0.05$ ), whereas median serum sodium level significantly increased from $136.0 \mathrm{mmol} / \mathrm{L}$ to $139.0 \mathrm{mmol} / \mathrm{L}(\mathrm{p}<$ 0.001). Conclusion: Potassium added $(20 \mathrm{mmol} / \mathrm{L})$ IVF solution reduces the risk of developing "hospitalacquired hypokalemia" in children who are not in states of AVP excess in maintenance fluid therapy. It is worthwhile to study prospectively in a larger number of sick children.
\end{abstract}

Keywords: Hyponatremia; Hypokalemia; Hypotonic

*Conflict of interest: None to declare.

${ }^{\#}$ Corresponding author.
Intravenous Fluid; Maintenance Fluid Therapy; Potassium Content

\section{INTRODUCTION}

Intravenous fluid (IVF) prescription practices until recently have been based upon the original description of maintenance fluid requirements by Holliday and Segars in 1957 [1]. Their pioneering work was performed in healthy breastfed children and was based on calorific requirements; they advised that if IVF was necessary, hypotonic fluid should be used at rates based on body weight. In the past decade, however, there have been several articles suggesting that the use of hypotonic IVF puts hospitalized children at a greater risk of developing life-threatening hyponatremia [2-5]. Hyponatremia in otherwise healthy children with acute illnesses, called hospital-acquired hyponatremia, is considered to be mainly caused by increased arginine vasopressin (AVP) production: i.e., dilution of extracellular fluid caused by an impaired free water excretion due to excess AVP seems to contribute to development of hyponatremia [3-5]. To reduce its risk, the National Patient Safety Agency (NPSA) in UK issued alert 22 in March 2007 [6]. The recommendations of the alert were to use isotonic solutions for some children at high risk of hyponatremia, instead of the previously most commonly used IVF ( $0.18 \%$ saline $/ 4 \%$ dextrose) for maintenance fluid therapy in children.

On the contrary, hypokalemia defined as a serum potassium concentration $<3.5 \mathrm{mmol} / \mathrm{L}$ has rarely drawn attention despite our insistence $[7,8]$, while it is a common and potentially serious electrolyte disorder $[9,10]$. Hypokalemia in hospitalized patients is mostly hospitalacquired and coexistence with hyponatremia [11]. Furthermore, it is of note that one-fourths of hypokalemic children were not receiving potassium in their IVF [12].

Based on these findings, we consider that potassium should be added into IVF and this study was conducted to validate the potassium added IVF for prevention of the 
hypokalemia in children receiving maintenance fluid therapy.

\section{PATIENTS AND METHODS}

This retrospective trial was conducted at the Kansai Medical University Hirakata Hospital, a tertiary care pediatric hospital. The medical records of the patients who admitted between November, 2008 and December, 2009 and required maintenance fluid therapy using IVF were investigated. Charts were reviewed for clinical characteristics, such as patient age, gender, diagnosis or details of administration of IVF. Laboratory data were also reviewed for blood urea nitrogen, serum creatinine, and serum levels of sodium ( $\mathrm{Na}$ ) and potassium (K).

Blood sampling were performed at least twice, i.e., just before IVF administration (T0) and at a median of 48 hours after IVF administration (T1). Soon after initial blood sampling, all patients received hypotonic IVF administration because of poor oral water intake: parenteral fluid therapy was continued till they could supply a demand of water requirements orally. Daily water requirements were calculated based on the formula proposed by Holliday and Segar [1]: the amount of daily IVF was decided by deduction of estimated oral intake from the daily water requirements and was infused evenly during parenteral fluid therapy.

Hypotonic IVF named Solita-T2 ${ }^{\mathrm{R}}$ (Na $84 \mathrm{mmol} / \mathrm{L}$, K $20 \mathrm{mmol} / \mathrm{L}, \mathrm{Cl} 66 \mathrm{mmol} / \mathrm{L}$, glucose 3.2\%), which is a commercially available IVF in Japan was used for all patients. Its composition is close equivalent to $0.45 \%$ saline/5\% dextrose (Na $77 \mathrm{mmol} / \mathrm{L}, \mathrm{K} 0 \mathrm{mmol} / \mathrm{L}, \mathrm{Cl} 77$ $\mathrm{mmol} / \mathrm{L}$, dextrose 5\%) except K content.

The following patients in states of AVP excess were excluded from the analysis: children requiring water restriction because of the high risk of developing syndrome of inappropriate antidiuretic hormone secretion, such as meningitis, encephalitis, acute bronchiolitis or post-operative condition [5]; children with evident dehydration; children demanding only small amount of IVF for maintenance fluid therapy (at a rate of less than $10 \mathrm{ml} /$ hour). Exclusion criteria also included renal disease, cardiac dysfunction, and known adrenal dysfunction.

Hyponatremia was defined as serum Na level $<135$ $\mathrm{mmol} / \mathrm{L}$ and hypokalemia as serum $\mathrm{K}$ level $<3.5 \mathrm{mmol} / \mathrm{L}$. The rate of change in serum $\mathrm{Na}$ or $\mathrm{K}$ was calculated as following: [serum level of $\mathrm{Na}$ or $\mathrm{K}$ at $\mathrm{T} 1$ ] - [serum level of $\mathrm{Na}$ or $\mathrm{K}$ at $\mathrm{T} 0$ ] divided by the number of hours between $\mathrm{T} 0$ and $\mathrm{T} 1$.

Because the serum levels of $\mathrm{Na}$ and $\mathrm{K}$, and their rate of change or absolute change were not normally distributed, the difference was tested using the Wilcoxon signed rank test. A level of $\mathrm{p}<0.05$ by two-tailed analysis was accepted as statistically significant.

\section{RESULTS}

Table 1 showed both the demographic data of the 41 patients (male 27, female 14) and the summary of the results. The diagnoses of the subjects were Kawasaki disease in 26, acute bronchopneumonia in 10, urinary tract infection in 2, occult bacteremia in 2, epileptic seizure in 1. Median age of patients was 3.01 years (interquartile range [IQR] 1.11, 4.82).

Table 1. Patients' characteristics and summary of the data.

\begin{tabular}{ll}
\hline Total number of subjects (male/female) & $41(27 / 14)$ \\
\hline Age of subjects (median [IQR]) & $3.01[1.11,4.82]$ \\
Administered volume of IVF (mL/kg/day; median [IQR]) & $44.4[28.2,62.3]$ \\
Hours between T0 and T1 (median [IQR]) & $48[24,48]$ \\
Rate of IVF administration (mL/hour; median [IQR]) & $20[20,30]$ \\
[K] data (median [IQR]) at T0 & $4.30(4.10,4.65)$ \\
No. of patients with [K] < 3.5 mmol/L (\%) at T0 & $1(2.4 \%)$ \\
[K] data (median [IQR]) at T1 & $4.10(3.90,4.50)$ \\
No. of patients with [K] $<3.5 \mathrm{mmol} / \mathrm{L}(\%)$ at T1 & $1(2.4 \%)$ \\
Rate of change [K] (mmol/L/hr) & $-0.004[-0.014,0.004]$ \\
Absolute change in [K] (mmol/L) & $-0.10[-0.50,0.15]$ \\
No. of patients with a fall in [K] (\%) & $23(56 \%)$ \\
[Na] data (median [IQR]) at T0 & $136.0(135.0,137.5)$ \\
No. of patients with [Na] $<135 \mathrm{mmol} / \mathrm{L}(\%)$ at T0 & $9(22 \%)$ \\
[Na] data (median [IQR]) at T1 & $139.0[137.0,140.0]$ \\
No. of patients with [Na] $<135 \mathrm{mmol} / \mathrm{L}(\%)$ at T1 & $1(2.4 \%)$ \\
Rate of change [Na] $(\mathrm{mmol} / \mathrm{L} / \mathrm{hr})$ & $+0.06[0.04,0.12]$ \\
Absolute change in [Na] $(\mathrm{mmol} / \mathrm{L})$ & $+3.0[1.0,4.0]$ \\
No. of patients with a fall in [Na] (\%) & $4(9.8 \%)$ \\
\hline
\end{tabular}

IQR: interquartile range; IVF: intravenous fluid; [Na]: serum sodium concentration; [K]: serum potassium concentration; T0: time of blood sampling before IVF; T1: time of blood sampling after IVF administration. 
The period of IVF administration varied from 24 hours to 120 hours (median 72 hours) and daily administered volume of IVF was ranging from $19.6 \mathrm{ml} / \mathrm{kg} /$ day to 90.7 $\mathrm{ml} / \mathrm{kg} /$ day (median 44.4; IQR 28.2, 62.3).

In regard to serum level of $\mathrm{K}$, there was no significant difference in values between $\mathrm{T} 0$ and $\mathrm{T} 1$ : median serum values of $\mathrm{K}$ were $4.30 \mathrm{mmol} / \mathrm{L}$ (IQR $4.10,4.65$ ) at T0 and $4.10 \mathrm{mmol} / \mathrm{L}$ (IQR 3.90, 4.50) at T1 (p > 0.05, Figure 1, right panel). Prevalence of hypokalemia also did not change (T0: $2.4 \%$, T1: $2.4 \%$ ). The median rate of change in serum $\mathrm{K}$ concentration was $-0.004 \mathrm{mmol} / \mathrm{L} /$ hour (IQR $-0.014,+0.004$ ) and the median absolute change was $-0.100 \mathrm{mmol} / \mathrm{L}$ (IQR $-0.500,+0.150$ ). Twenty-three patients (56\%) experienced a drop in serum $\mathrm{K}$ level: the maximum rate of fall and the maximum absolute change were $-0.042 \mathrm{mmol} / \mathrm{L} / \mathrm{hour}$ and $-1.40 \mathrm{mmol} / \mathrm{L}$, respectively.

While median serum level of $\mathrm{Na}$ was $136.0 \mathrm{mmol} / \mathrm{L}$ (IQR 135.0, 137.5) at T0, it increased significantly to $139.0 \mathrm{mmol} / \mathrm{L}$ (IQR 137.0, 140.0) at T1 (p < 0.001, Figure 1, left panel). Accordingly, the number of patients with hyponatremia decreased from $9(22 \%)$ at T0 to 1 $(2.4 \%)$ at $\mathrm{T} 1$. Serum $\mathrm{Na}$ level increased by +0.06 $\mathrm{mmol} / \mathrm{L} /$ hour as median rate of change (IQR +0.04 , +0.12 ), and the absolute change in serum $\mathrm{Na}$ level was $+3.0 \mathrm{mmol} / \mathrm{L}$ as median (IQR +1.00, +4.00). Only four patients $(9.8 \%)$ experienced a drop in serum Na level: the maximum rate of fall and the maximum absolute change were $-0.125 \mathrm{mmol} / \mathrm{L} /$ hour and $-3.00 \mathrm{mmol} / \mathrm{L}$, respectively.

\section{DISCUSSION}

In the practical setting, most children admitted to the hospital receive maintenance fluid therapy because of

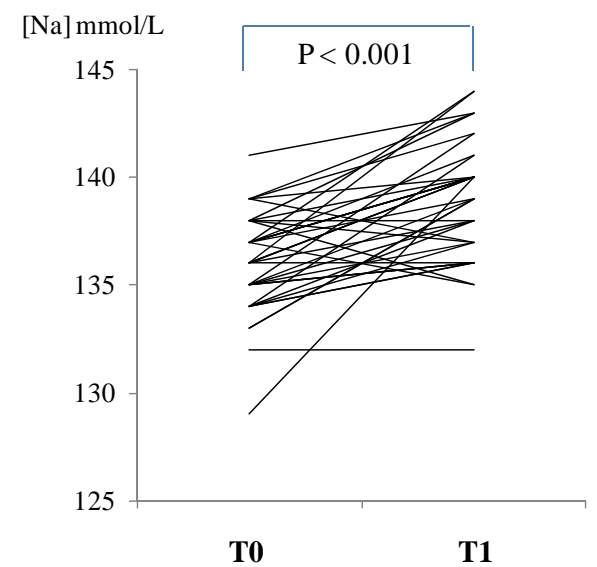

poor oral intake of water. The basic principles for maintenance fluid therapy in children were established with Holliday and Segar's landmark paper in 1957 [1] describing a simple formula for determining the maintenance need for water $(100 \mathrm{~mL} / \mathrm{kg}$ for the first $10 \mathrm{~kg}$ of bodyweight, $50 \mathrm{~mL} / \mathrm{kg}$ for the next $10 \mathrm{~kg}$, and $20 \mathrm{~mL} / \mathrm{kg}$ for bodyweight exceeding $20 \mathrm{~kg}$ ). They also postulated that $3 \mathrm{mmol}$ of $\mathrm{Na}, 2 \mathrm{mmol}$ of $\mathrm{K}$, and $2 \mathrm{mmol}$ of $\mathrm{Cl}$ should be given to children for each $100 \mathrm{ml}$ of water required. Accordingly, "hypotonic" IVF solution, equivalent to $0.18 \%$ saline $/ 4 \%$ dextrose with or without potassium has been considered to be suitable for maintenance fluid therapy for children.

In the past decade, however, it has been reported that the infusion of hypotonic IVF in otherwise healthy children with acute illnesses may cause hyponatremia named as "hospital-acquired hyponatremia" [2-5]. Though the pathophysiological basis for "hospital-acquired hyponatremia" is not fully understood, it is considered to be caused by administration of hypotonic IVF such as $0.18 \%$ saline $/ 4 \%$ dextrose to sick children, who demonstrated increased AVP production induced by non-osmotic stimuli [2-5]. As increasing evidence has shown that hypotonic maintenance IVF can lead to potentially fatal hyponatremia and hyponatremia is a rather serious condition than previously believed [13], recommendations by Holliday and Segar for prescribing hypotonic IVF solution [1] need to be reassessed.

To reduce the risk of "hospital-acquired hyponatremia”, the NPSA issued alert 22 [6]. The recommendations of the alert were to use either $0.9 \%$ or $0.45 \%$ saline with dextrose instead of the previously most commonly used IVF (0.18\% saline/4\% dextrose) for maintenance fluid therapy in children.

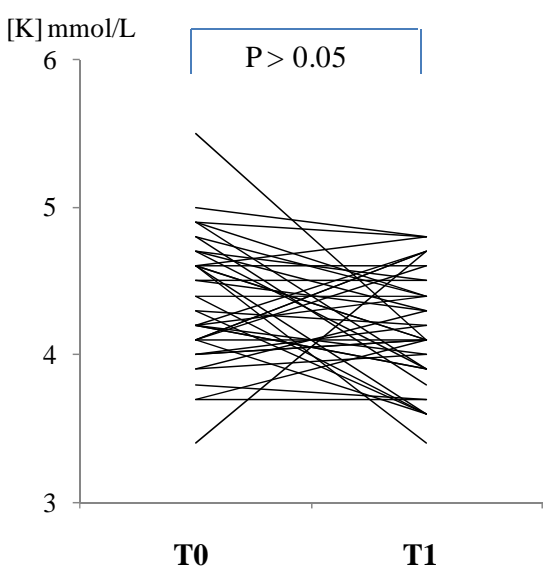

Administration of potassium added IVF solution named as Solita-T2 ${ }^{\mathrm{R}}(\mathrm{Na} 84 \mathrm{mmol} / \mathrm{L}, \mathrm{K} 20 \mathrm{mmol} / \mathrm{L}, \mathrm{Cl} 66$ $\mathrm{mmol} / \mathrm{L}$, glucose $3.2 \%)$ significantly increased $[\mathrm{Na}](\mathrm{p}<0.001)$ without significant change in $[\mathrm{K}](\mathrm{p}>0.05)$. [Na]: serum sodium concentration; $[\mathrm{K}]$ : serum potassium concentration; T0: time of blood sampling before IVF administration; T1: time of blood sampling after IVF administration.

Figure 1. Changes in serum levels of $\mathrm{Na}$ and $\mathrm{K}$ in children receiving maintenance fluid therapy. 
On the contrary, hypokalemia has drawn much less attention despite our insistence $[7,8]$, while it is a common (10\% - 20\% in hospitalized patients) and potentially serious electrolyte disorder $[9,10]$. This is because it is only a problem when it is severe. Severe hypokalemia causes muscle weakness, palpitations and cardiac dysrhythmias. For this reason, frequent measurement of serum potassium is mandatory otherwise hypokalemia might be overlooked until it becomes severe. Several authors have reported the increased risk of hypokalemia in patients receiving IVF with low or nil potassium content: Armon et al. reported that approximately half of children received IVF without potassium and that 23\% of children receiving IVF were hyopokalemic, of whom $24 \%$ were not receiving potassium in their IVF [12]; Crop et al. reported that $12 \%$ of adult patients with hypokalemia were identified and $71 \%$ of patients had hospital-acquired hypokalemia [11]; Sharifi, et al. confirmed that Ringers solution containing only $4 \mathrm{mmol} / \mathrm{L}$ of potassium has a higher risk of development of hypokalemia compared to oral rehydration solution containing 20 - 30 $\mathrm{mmol} / \mathrm{L}$ of potassium [14].

Given these findings, adding $20 \mathrm{mmol} / \mathrm{L}$ of potassium in IVF for maintenance fluid therapy is recommended [15] and we consider the ideal composition of IVF solution for maintenance fluid therapy as following: $\mathrm{Na} 70$ $90 \mathrm{mmol} / \mathrm{L}, \mathrm{K} 20 \mathrm{mmol} / \mathrm{L}, \mathrm{Cl} 60$ - $80 \mathrm{mmol} / \mathrm{L}$, glucose $3 \%$ - 5\%. Consequently, IVF solution at our ward has been changed from Solita-T3 ${ }^{\mathrm{R}}$ to Solita-T2 ${ }^{\mathrm{R}}$, both of which are commercially available IVF solutions in Japan: the former's composition ( $\mathrm{Na} 35 \mathrm{mmol} / \mathrm{L}, \mathrm{K} 20 \mathrm{mmol} / \mathrm{L}$, $\mathrm{Cl} 35 \mathrm{mmol} / \mathrm{L}$, glucose $4.3 \%$ ) is close equivalent to $0.18 \%$ saline $/ 4 \%$ dextrose and the latter's composition (Na $84 \mathrm{mmol} / \mathrm{L}, \mathrm{K} 20 \mathrm{mmol} / \mathrm{L}, \mathrm{Cl} 66 \mathrm{mmol} / \mathrm{L}$, glucose $3.2 \%$ ) is close equivalent to $0.45 \%$ saline except potassium content.

Aims of our study were to validate the Solita- $T 2^{\mathrm{R}}$ for prevention of "hospital-acquired hypokalemia" during maintenance fluid therapy in children who are not in states of AVP excess. Therefore, children at high risk of hyponatremia, such as meningitis, encephalitis, acute bronchiolitis, post-operative condition, children with evident dehydration, renal disease, cardiac dysfunction, and known adrenal dysfunction were excluded from the study. To reduce the risk of hyponatremia in these children, isotonic solutions should be used as the NPSA alert recommends [6].

As a result, we confirmed the usefulness of Solita-T2 ${ }^{\mathrm{R}}$ for prevention of hospital-acquired hypokalemia in maintenance fluid therapy for these children: there was no significant change in serum potassium concentration and mild hypokalemia (3.4 mmol/L) developed only in one patient (2.4\%) as shown in the Table 1 and the Figure 1. These were in contrast to the previous reports showing high risk of developing hospital-acquired hypokalemia $[11,14]$. Thus, it is suggested that potassium added IVF in maintenance fluid therapy results in less fall in serum $\mathrm{K}$ concentration. In addition, the risk of hospital-acquired hyponatremia was not increased either in this setting by this IVF solution as shown in the Table $\mathbf{1}$ and the Figure 1.

It is currently unknown what level of serum potassium or what situations increase the risk of hypokalemia related adverse events. Unwin et al. stated that the danger of hypokalemia increases under general anesthesia and the threshold serum potassium concentration is less than 2.6 $\mathrm{mmol} / \mathrm{L}[16]$.

On the contrary, in order to prevent iatrogenic hyperkalemia, special attention should be given on the oral intake of potassium in children receiving IVF containing high concentration of potassium, such as Solita-T2 ${ }^{\mathrm{R}}$. For this purpose, frequent measurement of serum potassium (every 12 hours) is strongly recommended.

In conclusion, although the number of studied patients is small, we believe that prescription of potassium added (20 mmol/L) IVF solutions reduce the risk of developing "hospital-acquired hypokalemia” during maintenance fluid therapy in children who are not in states of AVP excess. It is worthwhile to study prospectively in a larger number of sick children.

\section{ACKNOWLEDGEMENTS}

This study was partly supported by the Mami Mizutani Foundation.

\section{REFERENCES}

[1] Holliday, M.A. and Segar, W.E. (1957) The maintenance need for water in parenteral fluid therapy. Pediatrics, 19, 823-832.

[2] Halberthal, M., Halperin, M.L. and Bohn, D. (2001) Lesson of the week: Acute hyponatraemia in children admitted to hospital: Retrospective analysis of factors contributing to its development and resolution. British Medical Journal, 322, 780-782. doi:10.1136/bmj.322.7289.780

[3] Moritz, M.L. and Ayus, J.C. (2003) Prevention of hospital-acquired hyponatremia: A case for using isotonic saline. Pediatrics, 111, 227-230.

doi:10.1542/peds.111.2.227

[4] Moritz, M.L. and Carlos, A.J. (2007) Hospital-acquired hyponatremia - Why are hypotonic parenteral fluids still being used? Nature Clinical Practice Nephrology, 3, 374-382. doi:10.1038/ncpneph0526

[5] Kaneko, K. (2010) Hospital-acquired hyponatremia in children: Epidemiology, pathophysiology, and prevention. Journal of Pediatric Biochemistry, 1, 39-44.

[6] NPSA (2007) Reducing the risk of hyponatraemia when administering intravenous infusions to children. Alert no. 22, National Patient Safety Agency.

http://www.nrls.npsa.nhs.uk/resources/?entryid45=59809 


\section{\&q $=0 \%$ c2\%ac $2007 \%$ c2\%ac\&p=2}

[7] Kaneko, K. (2010) Don’t forget potassium! European Journal of Pediatrics, 169, 1041. doi:10.1007/s00431-010-1167-x

[8] Kaneko, K., Shimojima, T. and Kaneko, K. (2004) Risk of exacerbation of hyponatremia with standard maintenance fluid regimens. Pediatric Nephrology, 19, 11851186. doi:10.1007/s00467-004-1559-0

[9] Halperin, M.L. and Kamel, K.S. (1998) Potassium. Lancet, 352, 135-140.

[10] Gennari, F.J. (1998) Hypokalemia. New England Journal of Medicine, 339, 451-458. doi:10.1056/NEJM199808133390707

[11] Crop, M.J., Hoorn, E.J., Lindemans, J. and Zietse, R. (2007) Hypokalaemia and subsequent hyperkalaemia in hospitalized patients. Nephrology Dialysis Transplantation, 22, 3471-3477. doi:10.1093/ndt/gfm471

[12] Armon, K., Riordan, A., Playfor, S., Millman, G., Khader, A. and Paediatric Research Society (2008) Hyponatrae- mia and hypokalaemia during intravenous fluid administration. Archives of Disease in Childhood, 93, 285-287. doi:10.1136/adc.2006.093823

[13] Moritz, M.L. and Ayus, J.C. (2010) New aspects in the pathogenesis, prevention, and treatment of hyponatremic encephalopathy in children. Pediatric Nephrology, 25, 1225-1238. doi:10.1007/s00467-009-1323-6

[14] Sharifi, J., Ghavami, F., Nowrouzi, Z., Fouladvand, B., Malek, M., Rezaeian, M. and Emami, M. (1985) Oral versus intravenous rehydration therapy in severe gastroenteritis. Archives of Disease in Childhood, 60, 856860. doi:10.1136/adc.60.9.856

[15] Assadi, F. and Copelovitch, L. (2003) Simplified treatment strategies to fluid therapy in diarrhea. Pediatric Nephrology, 18, 1152-1156. doi:10.1007/s00467-003-1303-1

[16] Unwin, R.J., Luft, F.C. and Shirley, D.G. (2011) Pathophysiology and management of hypokalemia: A clinical perspective. Nature Reviews Nephrology, 7, 75-84. doi:10.1038/nrneph.2010.175 